\title{
Development of Curriculum + Community Enterprise for Restoration Science: A Formative Model for Educational \\ Partnerships
}

\author{
Michelle Molina, Erica Watson-Currie \\ SmartStart Evaluation \& Research, Irvine, USA
}

\author{
Lauren B. Birney \\ Pace University, New York, USA
}

\begin{abstract}
The Curriculum + Community Enterprise for Restoration Science (CCERS) is an educational model designed to increase the quality and effectiveness of Science, Technology, Engineering, Mathematics, and Computer Science (STEM-C) education in urban public middle schools through restoration science; increase knowledge and instructional skill of educators who work in economically disadvantaged neighborhoods; and increase public middle school students' knowledge of and interest in STEM-C. The model consists of five interrelated pillars, to create "wrap around" educational programming for disadvantaged urban students in New York City. The CCERS is an example of a complex partnership built upon formal and informal partnerships between universities, foundations, K-12 institutions, community organizations, and cultural institutions primarily from New York City. While the project will generate scientific research, provide educational resources, and contribute to educational research knowledge, an overarching goal is to create a replicable model applicable to other locations in need of restoration science educational projects.
\end{abstract}

Keywords: education, STEM, teaching, community, partnerships

In its current iteration, the curriculum focuses on the ecology of New York City waterways. Figure 1 shows a list of partnering organizations; however, as the project progresses, participating organizations may change. Students are learning core STEM-C concepts through discussions and activities focusing on local keystone species (e.g., oysters), how these species influence their ecosystems, while participating in restoring their local environments. CCERS lessons are designed to encourage students to tie scientific concepts to real world issues in their local communities and foster a sense of stewardship. As the curriculum is implemented, subsequent evaluations and research will assess the effectiveness of its myriad components. Lessons plans integrate Project Based Learning (PBL) and Bybee's 5 Emodel (Bybee, Taylor, Gardner, Van Scotter, Carlson-Powell, Westbook, \& Landes, 2006) for Biological Science Curriculum Study (BSCS). PBL requires students to work on a well-defined question almost independently of their teacher: students create questions, and decide how to tackle those questions (Wandersman et al., 2008). The 5E model incorporates these ideas into five structured phases: engagement, exploration, explanation, elaboration, and evaluation. The 5E model takes principles from cognitive science to improve students' learning, thereby giving educators a framework for making learning active (Bybee et al., 2006).

Michelle Molina, MA, SmartStart Evaluation \& Research.

Erica Watson-Currie, Ph.D., SmartStart Evaluation \& Research.

Lauren B. Birney, Ed.D., School of Education, Pace University. 
The purpose of this paper is to (1) describe the current form of the CCERS educational model and (2) share partners' suggestions for best practices from the initial phases to contribute to the understanding of complex scientific and educational partnerships. Authors focused on answering the following research questions:

What comprises the "curriculum plus community enterprise" local model?

Do the five programmatic pillars function independently and/or collectively as a system of interrelated STEM-C content delivery vehicles that are effective in changing educator and student disposition toward STEM-C content and environmental restoration and stewardship?

\begin{tabular}{|l|l|}
\hline \multirow{2}{*}{ CCERS Pillars \& Partners } \\
\hline Pillar 1: Teacher Fellowship & $\begin{array}{l}\text { - Columbia University - Lamont-Doherty Earth Observatory } \\
\text { - Pace University } \\
\text { • New York Harbor Foundation }\end{array}$ \\
\hline Pillar 2: Student Curriculum & - Pace University \\
\hline Pillar 3: Digital Platform & New York Harbor Foundation \\
\hline Pillar 4: Afterschool/ Mentoring & - NYC Department of Education \\
\hline Pillar 5: Community Exhibits & - Nood Shepherd Services \\
\hline
\end{tabular}

Figure 1. Partner Organizations.

\section{Paper Framework}

A project goal is to improve the quality and effectiveness of STEM-C education in urban public middle schools by forming partnerships between educators and scientists. This paper will use project leaders' descriptions to outline the overarching model's aims and objectives. Insights were gained from interviews and ethnographic observations of classroom activities and meetings. Through their descriptions, project leaders hope to provide others seeking to adopt this innovation as a guide through the beginning stages of implementation. According to Rogers (1983), there are four elements in the diffusion of innovations: innovation, communication channels, time, and social systems. These four elements will be used to guide the diffusion (or dissemination) of this model. This paper will serve as a means to open communication channels. According to this framework, high homophily, or the degree to which individuals are alike, facilitates communication in the diffusion process. Current project leaders have high homophily with their counterparts in other organizations who will lead future replication efforts, thus making project leaders' perspectives especially important to document. Rogers also lists five steps in the decision-making process in order to adopt an innovation: knowledge, persuasion, decision, implementation, and confirmation. Therefore, this paper seeks to (1) promote knowledge of the model using project leaders' perspectives, and (2) disclose insights to potential adopters regarding how the model functions.

\section{Method}

\section{Participants}

The research team collaborated with primary investigators to select 21 project leaders from the partnering 
organizations to participate in interviews. Researchers reviewed participants' involvement in the project, and confirmed their perceptions with primary investigators on the leadership team. Eight project leaders participated in the first round of exploratory interviews in February 2015. In May 2015, 15 project leaders participated in the second round of interviews. Six participated in both sets of interviews.

\section{Assessments and Measures}

Researchers employed longitudinal qualitative interviews (LQI) to obtain data in order to address the research questions listed above. LQI is used to study how individuals or groups "experience, interpret, and respond to change" by exploring themes across time using the characterizations as baselines (Hermanozicz, 2013, p. 189). Interviews included open-ended semi-structured questions. Researchers employed deductive reasoning to create an open and thematic coding scheme derived from the data itself. Researchers also used project documents (i.e., protocols, lesson plans, etc.), observations, and informal conversations with partners and educators to gain greater insights and contextualize interviews.

\section{Results}

The authors categorized data findings into two major categories. The CCERS model and components section begins to answer the research questions. The communication suggestions section is intended to provide potential adopters of the CCERS model guidelines on implementation.

\section{CCERS Model and Components}

Research Question 1: Overarching model. Project leaders' vision for the CCERS model is to create a curriculum for middle school students using restoration science to improve their environment while learning core STEM-C concepts:

(Our aim is to) build scalable curriculum for middle school students that revolves around restoration based science and education using experiential methods to actually make a difference in the community the students live in.

Long-term, the vision of the CCERS project is to create an educational partnership model that educators can use in other locations to promote restoration efforts:

Eventually, broaden this out to other environments and systems. So that students know more about the environment they are living in, its history, and how they can look after it. They can teach others as well.

Each of the model's five work groups is envisioned as a pillar. Members from various organizations collaborate and "share responsibility for specific outcomes" (Sundstorm, De Meuse, \& Futrell, 1990, p. 120). The five pillars are: teacher training fellowship, student curriculum, digital platform, afterschool and summer mentoring, and community exhibits. Partners focus on their own pillar's activities, and come together at monthly and/or quarterly meetings to collaborate:

Although each of those pillars is independent, they all have a common vision and common goals ... Everyone seems to be working in unison to get to those goals.

Each pillar provides its unique contribution to students' learning. By integrating their work, partners are creating well-rounded experiences for students across many educational settings. Figure 2 shows a diagram of the CCERS model. 


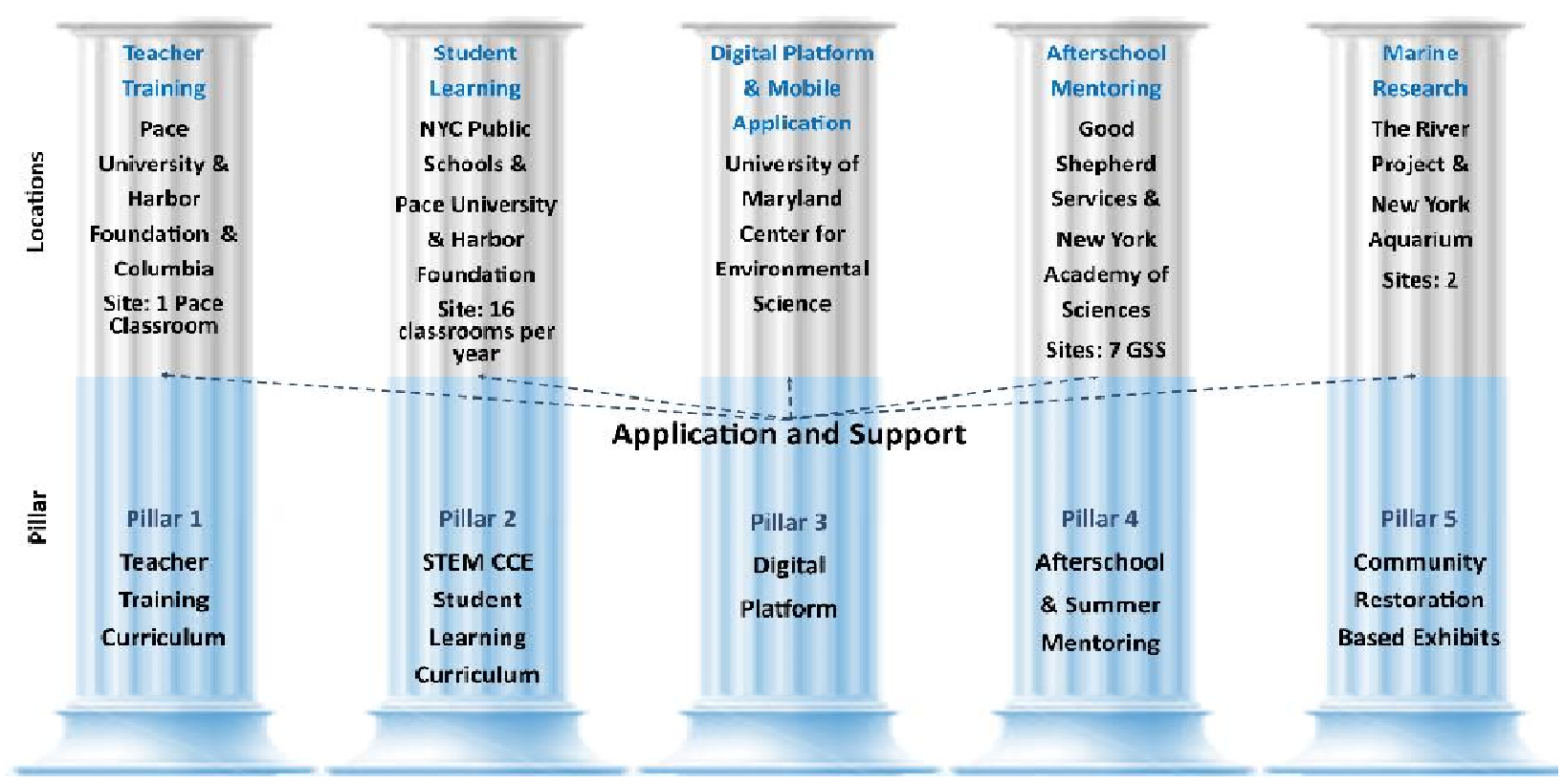

Figure 2. CCERS Educational Partnership Model Diagram.

Research Question 2: Pillar vision. The following summarizes project leaders' visions of each pillar as described in interviews with researchers, highlighting how individual pillars contribute to the model.

Pillar 1: Partners are further developing a curriculum, and training teachers to effectively integrate restoration science into their lesson plans. For instance, teachers are learning how to use scientific equipment at restoration stations (i.e., sites out in the waterfront near schools where students and teachers can find cages used to care for and monitor oyster growth), as well as how to incorporate the 5E model into their lessons. Partners want teachers to continue participating by discussing implementation strategies and sharing ideas for incorporating restoration science into their lessons.

Pillar 2: Partners seek to increase students' STEM-C content knowledge through classroom lessons developed in partnership with teachers. For example, students will use data collected by students and citizen scientists at restoration stations to ask questions, analyze data, and engage in argumentation about their local environments. They will also learn about the local ecology. Ultimately, partners want the implementation of this curriculum to continuously increase.

Pillar 3: Partners are developing a digital repository where materials and data can be shared, discussed and reviewed by teachers, students, and potentially citizen scientists. Partners want this platform to unite partners and promote environmental awareness throughout the community. The mobile application being developed will be used by students to collect data (e.g., current weather conditions, oyster measurements, etc.) at restoration stations. A digital dashboard will enable them to compare their data with that collected by others, and download charts and graphs for use in end-of-term reports and presentations on what they've learned.

Pillar 4: Partners are enhancing student knowledge of restoration science in out-of-school time settings by expanding curriculum. Scientists partnering with Youth Development Specialists are teaching students core STEM-C concepts through restoration science in afterschool programs and summer camps. For example, one lesson allows students to explore the oyster's role in the history of New York Harbor. During another lesson, students dissect oysters to learn about anatomy and how different anatomical structures enable oysters to clean 
the water, and allow the oysters to survive. Eventually, partners want to increase implementation reaching more students.

Pillar 5: Partners seek to promote students' inquiry on the biodiversity in their local environment, as well as increase connections between schools and cultural institutions. Partners want to educate students and the public about the history and importance of oysters through useful and relevant exhibits. To do so, teachers and afterschool educators will take their participating students to The River Project to tour the lab, participate in hands-on-minds-on activities, as well as discuss water quality monitoring, oyster reefs, and oyster anatomy.

Together the layering of each pillar's unique contribution is intended to produce a cumulative impact, increasing students' understanding of their local environments and how to restore them, fostering stewardship while also providing engaging STEM-C content.

Communication suggestions. Based on their experiences during this first phase of implementation, partners emphasized the importance of communication in the development of effective partnerships. Specifically, partners suggest others seeking to replicate this model (1) clearly define roles and (2) streamline decision-making early on.

(1) Partners' roles should be clear:

Individual and organizational roles must be clearly defined from the outset. Although it is often challenging, partners would like their future counterparts to understand the importance of clarity. Ambiguous roles and the desire to have a definitive leader are hallmarks of newly formed groups; as groups mature, roles become clear and leadership is shared based on those roles (Schein, 2004).

(2) Decisions should be streamlined:

Create an effective decision-making system early on, which enables partners to move through obstacles faster. Effective partnerships create policies and procedures that bolster collaboration while encouraging decision-making and program implementation (Mohram \& Cummings, 1989). For example, partners have found delegating tasks to be effective. This aligns with Roberson and Choi's (2010) suggestion of embracing a team-based organizational design where project leaders delegate tasks to smaller, more focused groups based on members' expertise.

\section{Discussion}

The goal of the CCERS model is to increase the quality and effectiveness of STEM-C teaching and learning for urban public middle school students. By implementing this educational partnership model, educators in a variety of settings will be able to connect students to restoration efforts in their local environments making STEM-C concepts more meaningful. Long-term, the development of model will provide a roadmap for educators and scientists in other locations to follow.

By adopting the CCERS educational partnership model, educators and scientists will provide an effective STEM-C curriculum to a broader range of students. This model fosters collaboration between educators and scientists across multiple educational settings to create comprehensive experiences for students. These mutually beneficial partnerships will allow educators to engage students by showcasing how concepts have real-world implications within their communities (Bouillion \& Gomez, 2001). Furthermore, by covering similar topics across multiple settings, the model also enables educators to reinforce each topic's importance. Each of these educational settings brings a unique opportunity to impact the learning experiences of students. Teacher training (or professional development) is key to enhancing education as it increases positive student outcomes 
leading to continuous improvements in teachers' classroom practices (Katzenmeyer \& Moller, 2001). Engaging middle school classroom curriculum is also crucial because students often become disinterested in their education during the early years of adolescence, resulting in students who are not properly prepared to succeed in high school and beyond (Balfanz \& Mac Iver, 2000). The use of technology, such as a mobile application, in educational settings also has positive impacts on students' content knowledge, attitudes towards technology, motivation and task engagement, as well as higher order thinking (Brown, 2007; Eyyam \& Yaratan, 2014; Lòpez-Pèrez, Pèrez-Lòpez, Rodrìguez-Ariza, \& Argente-Linares, 2013). Likewise, field trips to cultural institutions produce positive effects on visitors, such as higher recall and increased interest in science careers, encouraging disenfranchised learners to identify as scientists, improving critical thinking, and increasing connections to content (Behrendt \& Franklin, 2014; Dierking \& Falk, 1997; Greene, Kisida, \& Bowen, 2014; Naizer, 1993; Rahm \& Ash, 2008). Moreover, prior research has also shown afterschool programming can positively influence student outcomes; for example, by increasing collaborative learning, inquiry, the development of 21 st century skills, grade point average, and social capital (Miller, 2011; Sahin, Ayar, \& Adiguzel, 2014; Springer \& Diffily, 2012). The CCERS model will foster cohesiveness between settings, ensuring students are offered engaging curriculum that not only increases their STEM-C knowledge, but also promotes a sense of stewardship over their local environments by providing opportunities for self-motivated projects (Morgan, 2014).

\section{Conclusion}

This paper has described the composition and motivating factors of the CCERS educational partnership model, as well as how its components function independently and collectively, in the interest of, inspiring and facilitating future replication efforts. In addition, this paper also discussed suggestions from this initial phase, in order to simplify subsequent replication efforts. As implementation is still in its early stages, more research will be conducted to describe the model as it develops. Future research will specifically focus on how each pillar functions collectively as a system of interrelated STEM-C content delivery vehicles, by better describing each pillar and how they collaborate within the model. As the model develops, partners will gain new perspectives allowing for further contextualization of the model within the research and the emergence of additional partner suggestions.

\section{References}

Balfanz, R., \& Mac Iver, D. (2000). Transforming high-poverty urban middle schools into strong learning institutions: Lessons from the first five years of the talent development middle school. Journal of Education for Students Placed at Risk, 51(1-2), 137-158. doi:10.1080/10824669.2000.9671384

Baumgartner, E., \& Zabin, C. J. (2008). A case study of project-based. Environmental Educational Research, 97(2), 97-114.

Behrendt, M., \& Franklin, T. (2014). A review of research on school field trips and their value in education. International Journal of Environmental \& Science Education, 9, 235-245.

Bouillion, L. M., \& Gomez, L. M. (2001). Connecting school and community with science learning: Real world problems and school-community partnerships as contextual scaffolds. Journal of Research in Science Teaching, 38(8), 878-898.

Brown, C. (2007). Learning through multimedia construction-A complex strategy. Journal of Educational Multimedia and Hypermedia, 16(2), 93-124.

Bybee, R., Taylor, J., Gardner, A., Van Scotter, P., Carlson-Powell, J., Westbrook, A., \& Landes, N. (2006, June). The 5E instructional model: Origins, effectiveness, and applications. Retrieved 15 2016, March, from http://bscs.org/sites/default/files/_legacy/5E_Instructional_Model-Full_Report.pdf

Dierking, L. D., \& Falk, J. H. (1997). School field trips: Assessing their long-term impact. Curator, 40(3), 211-218. 
Eyyam, R., \& Yaratan, H. S. (2014). Impact of use of technology in mathematics lessons on student achievement and attitudes. Social Behavior and Personality, 42(Suppl.), S31-S42.

Greene, J. P., Kisida, B., \& Bowen, D. H. (2014). The educational value of field trips: Taking students to an art museum improves critical thinking skills, and more. Education Next, 14(1), 78.

Hermanozicz, J. C. (2013). The longitudinal qualitative interview. Qualitative Sociology, 36, 189-208.

Katzenmeyer, M., \& Moller, G. (2001). Awakening the sleeping giant: Helping teachers develop as leaders. Thousand Oaks, C.A.: Corwin Press.

Lòpez-Pèrez, M. V., Pèrez-Lòpez, M. C., Rodrìguez-Ariza, L., \& Argente-Linares, E. (2013). The influence of the use of technology on student outcomes in a blended learning context. Educational Technology Research and Development, 61, 625-638.

Miller, J. N. (2011). Contracted providers: Overcoming challenges in a portfolio school district. Center on Reinventing Public Education. Seattle, W.A.: University of Washington Bothell. Retrieved July 21, 2015, from $\mathrm{http} / / /$ www.crpe.org/sites/default/files/WP_CRPE_ContractedProviders_May11_0.pdf

Mohram, S. A., \& Cummings, T. G. (1989). The self-designing organization: Learning how to create high performance. Reading, M.A.: Addison-Wesley.

Morgan, E. E. (2014). Fostering stewardship and citizenship: Action research in place-based education (Unpublished Masters Thesis at Prescott College in Education, UMI Number: 1573451).

Naizer, G. L. (1993). Science and engineering professors: Why did they choose science as a career? School Science and Mathematics, 93(6), 321-324.

Rahm, J., \& Ash, D. (2008). Learning environments at the margin: Case studies of disenfranchised youth doing science in an aquarium and an after-school program. Learning Environments Research, 11(1), 49-62.

Robertson, P. J., \& Choi, T. (2010). Ecological governance: Organizing principles for an emerging era. Public Administration Review, 70, s89-s99.

Rogers, E. M. (1983). Diffusion of innovations (3 ed.). New York: The Free Press.

Sahin, A., Ayar, M. C., \& Adiguzel, T. (2014). STEM related after-school program activities and associated outcomes on student learning. Educational Sciences: Theory \& Practice, 14(1), 309-322. doi:10.12738/estp.2014.1.1876

Schein, E. H. (2004). Organizational culture and leadership (3 ed.). San Francisco, C.A.: Jossey-Bass.

Springer, K., \& Diffily, D. (2012). The relationship between intensity and breadth of after-school program participation and academic achievement: Evidence from a short-term longitudinal study. Journal of Community Psychology, 40(7), 785-798.

Sundstorm, E., De Meuse, K. P., \& Futrell, D. (1990). Work teams: Applications and effectiveness. American Psychologist, 45(2), 120-133.

Wandersman, A., Duffy, J., Flaspohler, P., Noonan, R., Lubell, K., Stillman, L., ... Saul, J. (2008). Bridging the gap between prevention research and practice: The interactive systems framework for dissemination and implementation. American Journal of Community Psychology, 41, 171-181. 